\title{
PERIODICITY AND POSITIVITY IN NONLINEAR NEUTRAL INTEGRO-DYNAMIC EQUATIONS WITH VARIABLE DELAY
}

\author{
MALIK BELAID, ABDELOUAHEB ARDJOUNI, and AHCENE DJOUDI
}

Abstract. Let $\mathbb{T}$ be a periodic time scale. We use Krasnoselskii's fixed point theorem for a sum of two operators to show new results on the existence of periodic and positive periodic solutions of the nonlinear neutral integro-dynamic equation with variable delay of the form

$$
\begin{aligned}
x^{\triangle}(t) & =-\int_{t-\tau(t)}^{t} a(t, s) x(s) \Delta s+Q(t, x(t-\tau(t)))^{\triangle} \\
& +G(t, x(t), x(t-\tau(t))), t \in \mathbb{T} .
\end{aligned}
$$

We invert this equation to construct a sum of a contraction and a completely continuous map which is suitable for applying Krasnoselskii's theorem. The uniqueness results of this equation are studied by the contraction mapping principle. The results obtained here extend the work of Mesmouli, Ardjouni and Djoudi [15].

MSC 2010. 34K13, 34K30, 34L30, 34K40.

Key words. Fixed points, integro-dynamic equations, periodic solutions, positive solutions, time scales.

\section{REFERENCES}

[1] M. Adivar and Y.N. Raffoul, Existence of periodic solutions in totally nonlinear delay dynamic equations, Electron. J. Qual. Theory Differ. Equ., 2009, 1, 1-20.

[2] A. Ardjouni and A. Djoudi, Existence of periodic solutions for nonlinear neutral dynamic equations with variable delay on a time scale, Commun. Nonlinear Sci. Numer. Simul., 17 (2012), 3061-3069.

[3] A. Ardjouni and A. Djoudi, Existence of positive periodic solutions for nonlinear neutral dynamic equations with variable delay on a time scale, Malaya J. Mat., 2 (2013), 1, 6067.

[4] A. Ardjouni and A. Djoudi, Existence of periodic solutions for nonlinear neutral dynamic equations with functional delay on a time scale, Acta Univ. Palack. Olomuc. Fac. Rerum Natur. Math., 52 (2013), 1, 5-19.

[5] A. Ardjouni and A. Djoudi, Existence, uniqueness and positivity of solutions for a neutral nonlinear periodic dynamic equation on a time scale, J. Nonlinear Anal. Optim., 6 , 2, (2015), 19-29.

[6] M. Belaid, A. Ardjouni and A.Djoudi, Stability in totally nonlinear neutral dynamic equations on time scales, Int. J. Anal. Appl., 11 (2016), 2, 110-123.

The authors would like to thank the anonymous referee for his valuable comments.

DOI: $10.24193 /$ mathcluj.2020.2.02 
[7] L. Bi, M. Bohner and M. Fan, Periodic solutions of functional dynamic equations with infinite delay, Nonlinear Anal., 68 (2008), 1226-1245.

[8] M. Bohner and A. Peterson, Dynamic Equations on Time Scales. An Introduction with Applications, Birkhäuser, Boston, 2001.

[9] M. Bohner and A. Peterson, Advances in Dynamic Equations on Time Scales, Birkhäuser, Boston, 2003.

[10] T.A. Burton, Stability by Fixed Point Theory for Functional Differential Equations, Dover Publications, New York, 2006.

[11] S. Hilger, Ein Masskettenkalkül mit Anwendung auf Zentrumsmanningfaltigkeiten, $\mathrm{PhD}$ Thesis, Universität Würzburg, 1988.

[12] E.R. Kaufmann and Y.N. Raffoul, Periodic solutions for a neutral nonlinear dynamical equation on a time scale, J. Math. Anal. Appl., 319 (2006), 1, 315-325.

[13] E.R. Kaufmann and Y. N. Raffoul, Periodicity and stability in neutral nonlinear dynamic equations with functional delay on a time scale, Electron. J. Differential Equations, 2007, 27, 1-12.

[14] V. Lakshmikantham, S. Sivasundaram and B. Kaymarkcalan, Dynamic Systems on Measure Chains, Kluwer Academic Publishers, Dordrecht, 1996.

[15] M.B. Mesmouli, A. Ardjouni and A. Djoudi, Existence of periodic and positive solutions of nonlinear integro-differential equations with variable delay, Nonlinear Stud., 22 (2015), 2, 201-212.

[16] M.B. Mesmouli, A. Ardjouni and A. Djoudi, Existence and stability of periodic solutions for nonlinear neutral differential equations with variable delay using fixed point technique, Acta Univ. Palack. Olomuc. Fac. Rerum Natur. Math., 54 (2015), 1, 95-108.

[17] M.B. Mesmouli, A. Ardjouni and A. Djoudi, Study of periodic and nonnegative periodic solutions of nonlinear neutral functional differential equations via fixed points, Acta Univ. Sapientiae Math., 8 (2016), 2, 255-270.

[18] D.R. Smart, Fixed point theorems, Cambridge Tracts in Mathematics, Vol. 66, Cambridge University Press, London-New York, 1974.

Received December 20, 2018

Accepted March 19, 2019
University of Annaba

Department of Mathematics

P.O. Box 12, Annaba, Algeria

E-mail: malikbelaid51@gmail.com

University of Souk Ahras

Department of Mathematics and Informatics

P.O. Box 1553, Souk Ahras, Algeria

E-mail: malikbelaid51@gmail.com

University of Annaba

Department of Mathematics

P.O. Box 12, Annaba, Algeria

E-mail: adjoudi@yahoo.com 